\title{
Sobre el derecho a la resistencia en Thomas Hobbes y John Locke
}

\author{
Adriana Vera Díaz \\ Universidad de Pamplona (Colombia)
}

Recibido: agosto 11 de 2019. Revisado: septiembre: 16 de 2019. Aceptado: noviembre 13 de 2019

Referencia norma APA: Vera, A. (2019). Sobre el derecho a la resistencia en Thomas Hobbes y John Locke. Rev. Guillermo de Ockham, 17(2), 51-59. doi: https://doi.org/10.21500/22563202.4234

\section{Resumen}

El empleo del derecho a la resistencia no tiende de alguna manera a realizar las aspiraciones populares, sino a defender o restaurar el orden establecido. Por tanto, al reconocer el derecho de resistencia se pretende que sea un medio para que el príncipe reflexione y de esta manera hacerle respetar la legalidad. Por ende, el presente escrito expondrá el pensamiento de Thomas Hobbes y John Locke y establecerá los posibles acuerdos y desacuerdos con respecto a sus teorías políticas, especialmente la que aquí concierne, a saber: el derecho a la resistencia.

Palabras clave: Thomas Hobbes, John Locke, derecho, resistencia, Estado

\section{On the right to resistance in Thomas Hobbes and John Locke}

\section{Summary}

The use of the right to resistance does not tend in any way to achieve popular aspirations, but to defend or restore the established order; Therefore, by recognizing the right of resistance, it is intended to work as a mean for the prince to reflect and as a result, get him to respect the lawfulness. Consequently, this paper will present Thomas Hobbes and John Locke's thinking and will establish possible agreements and disagreements regarding their political theories, especially the one that concerns here: the right to resistance.

Keywords: Thomas Hobbes, John Locke, rights, resistance, state, power. 
El Derecho a la resistencia tiene un significado en la historia del pensamiento político, pues se considera como la limitación del poder a la autoridad pública y del Estado y a su vez, la custodia de la libertad de una comunidad o pueblo, queriendo de esta manera conservar el bien común de los individuos que lo conforman. En esencia, se relaciona con la conservación del bien común de una comunidad en lo que corresponde a la justicia, además del imparcial y honrado mandato político y jurídico del Estado. Cabe señalar que el Estado apareció como una esfera neutra dentro de la sociedad para arbitrar las disputas en su interior, solo que con ello quedó desvirtuado lo esencial: el derecho político de resistir al poder, debido a que solo queda el propio Estado.

Esta problemática ha llamado la atención de varios pensadores, particularmente en el ámbito constitucional democrático, ya que la presencia, el consentimiento y hasta el afianzamiento jurídico del derecho de resistencia presume una visible contradicción entre el principio aceptado por acuerdo entre el mismo Estado con la obligación de preservar el derecho, y la teoría que recurre al empleo de la violencia para solventar el conflicto social. Es de resaltar que la mencionada contrariedad nos devela una gran inconsistencia, pues se aceptaría la violencia como herramienta política denotando con ello la negación misma de la Constitución.

Al respecto del derecho de resistencia, podemos constatar cómo Thomas Hobbes vio muy bien que toda insurrección que va contra del derecho establecido es ilegal y por tanto ilegítima, pero si triunfa implanta su propio derecho y se legitima. Con ello el Derecho - lo recto- comenzó a perder su autoridad confundiéndose con el poder; asimismo pasó a ser la forma normal de expresarse el poder político. Mientras que por otro lado, según John Locke si el poder llega al punto de perjudicar los derechos naturales - principalmente la libertad, seguido de la propiedad-, puede establecerse el derecho de sublevarse y proporcionarse unos gobernantes decididos a hacer del Estado un poder al servicio de las libertades esenciales de cada sujeto.

\section{Pensamiento político de Thomas Hobbes en su obra Leviatán. 0 la materia, forma y poder de una república eclesiástica y civil}

Thomas Hobbes, pensador influyente especialmente en el ámbito político y quien se enfoca en la exposición en torno al hombre artificial -el Estado-, en su texto más significativo, a saber: Leviatán. $O$ de la materia, forma y poder de una república eclesiástica y civil. Para ello inicia con una exégesis del hombre o sujeto, quien es el único capaz de crear ese "gran monstruo". Como nos lo indica Santos (2013):

El ser humano, como un engranaje más dentro de esa maquinaria perfecta que es el cosmos, debe continuar, a su vez, el designio impreso en la sucesión universal de causas eficientes, y, de la misma manera que su ser como hombre es un producto artificial de la naturaleza, él a su vez ha de construir otro hombre, mucho más perfecto: el Leviatán, o la persona moral del Estado (pp. 95-123).

Así, Hobbes da protagonismo al hombre pues solamente este es quien puede conocer y adaptarse a su vez al ambiente y así mismo buscar la satisfacción de sus pretensiones, lo que da paso al Leviatán como un organismo que imparte leyes y genera un equilibrio social. De este modo, en la segunda parte de su obra se centra en el estudio del hombre en sociedad, razón por la cual y para lo que a este apartado respecta, nos centraremos en las dos primeras partes del texto en mención.

Para el desarrollo de esta labor se comienza con el abordaje del conocimiento humano. Con base en el hecho de que el pensamiento del hombre se da por una representación o apariencia de alguna cualidad $\mathrm{u}$ otro accidente de un cuerpo externo, Hobbes conceptúa: "En efecto, no existe ninguna concepción en el intelecto humano que antes no haya sido recibida, totalmente o en parte, por los órganos de los sentidos" (Hobbes, 2014, p. 6). De acuerdo con lo antes dicho, el conocimiento solo se compone de un conglomerado de impresiones absolutamente pasivo, de forma que todo conocimiento natural es verdadero en cuanto se da (Cfr. Santos, 2013, 104). Es así que los sujetos actúan de acuerdo con los impulsos que reciben del exterior, lo que los lleva a evitar aquello que consideran desagradable y conseguir todo lo agradable posible. Aún más, el registro de las "consecuencias de nuestros pensamientos" se da gracias al lenguaje. Luego, por medio de las palabras se sustraen dichos actos de nuestra memoria. En palabras del autor: "la luz de la mente humana la constituyen las palabras claras o perspicuas, pero libres y depuradas de la ambigüedad mediante definiciones exactas" (Hobbes, 2014, p. 38).

A partir de este punto encontraremos lo que el filósofo inglés llama deliberación, ya que este acto implica poner un término a la libertad que tenemos de hacer u omitir según nuestro apetito o aversión; es aquí

1. Entiéndase esto como la característica de la razón en Hobbes, pues la razón descompone la situación que se presente ante ella y analizará según su experiencia los futuros posibles acontecimientos y así puede elegir los más convenientes.

$52<$ Universidad de San Buenaventura, Cali, Colombia 
donde el concepto hobbesiano de libertad del hombre se establece en función de una triple relación entre el poder, la deliberación y la voluntad (...) por ello, actúa libremente aquel que elije arrojar sus pertenencias al agua a fin de salvarse de un naufragio, aunque esa decisión haya sido precedida por una deliberación en la que se hace presente la relación causal necesaria entre evitar el naufragio y aligerar la carga de la nave (Peychaux, 2013, p. 150).

Dicho acto también puede recibir el nombre de voluntad, ${ }^{2}$ puesto que es motivado por los apetitos que impelen al hombre a estar en una búsqueda constante de poder, pues la voluntad le propicia un medio para conquistar un bien que detenta en el futuro.

Ahora bien, el problema que acá se presenta radica en que cuando lo agradable hay que compartirlo con otras personas; o, en caso contrario, las otras personas obstaculizan la consecución de aquellos deseos, observemos que para el filósofo en cuestión tres son las causas principales de la discordia, a saber: la competencia, la desconfianza y la gloria, porque mientras los hombres se encuentren viviendo sin un poder común que los atemorice, se encontrarán en condición o estado de guerra, una guerra de todos contra todos y mientras no exista un poder común al cual temer, todo puede ser injusto, puesto que la ley no existe. Pero hay más. El mayor de los poderes que se encuentra en los sujetos es el que se integra con los poderes de los demás, unidos por el consentimiento en una persona ya sea natural o civil (Cf. Hobbes, 2014, 69). De ahí, la importancia de la obediencia civil en Hobbes:

El afán de tranquilidad y de placeres sensuales dispone a los hombres a obedecer a un poder común, porque tales deseos les hacen renunciar a la protección que cabe esperar de su propio esfuerzo o afán. El temor a la muerte y a las heridas dispone a lo mismo, y por idéntica razón (Hobbes, 2014, p. 80).

Es decir, la condición natural del hombre es una condición de guerra, como se mencionó anteriormente de todos contra todos, en la que cada quien se encuentra gobernado por su razón y utiliza cualquier cosa como medio para defender o proteger su vida de aquellos enemigos, estableciendo de este modo la Ley de naturaleza que se concibe como una norma establecida por la razón, en la que se prohíbe a un sujeto hacer lo que pueda destruir su vida o privar de medios para su conservación. Lukac de Stier nos dice al respecto:
En el estado de naturaleza los hombres son una multitud, una colección de individuos particulares. Precisamente el problema de Hobbes consiste en construir una sociedad a partir de esa colección de individuos que, en el estado de naturaleza, consideran que tienen derecho a todo. Reducir la multiplicidad a una unidad consiste, para Hobbes, en la creación de una persona, en este caso una persona artificial (Lukac de Stier, 2015, p. 2).

Caso contrario del Derecho de naturaleza, pues aquí se plantea la condición natural como una libertad absoluta de hacer u omitir, ya que segun este derecho el hombre decide usar su poder como mejor le parezca con miras a una finalidad clara: la conservación de su propia naturaleza, de su propia vida. Es así que la ley está determinando u obligando a cualquiera de estas cosas o a las dos. En este aspecto, según Santos, Hobbes hace un esfuerzo para que la crueldad que se desata en el sujeto en su estado natural no sea objeto de calificativos morales, pues este estado es una confirmación de su cruda realidad. Por ello:

La libertad que implica el derecho natural se vuelve, de este modo, calamitosa, pues su misma existencia supone su negación. Mientras los hombres son libres de hacer todo, paradójicamente hay que afirmar que no son libres de hacer nada, ya que no cuentan con seguridad alguna, y se ven obligados a mantenerse en un estado de vigilancia constante frente a los demás hombres. Este es el motivo que hace a la razón clamar por la constitución del Leviatán, el cual no es sino una suma de los derechos naturales (Santos, 2013, p. 112).

De manera que la autodefensa es la mayor necesidad del ser humano, pero que debido a la escasez de optimizar las condiciones de vida los hombres han de hacer un contrato que Hobbes describe como "la mutua transferencia de derechos". Pero se ha de distinguir bien entre la trasferencia del derecho o transferencia como entrega de la cosa misma, pues la cosa puede ser entregada al mismo tiempo que se transfiere el derecho. Entonces, "uno de los contratantes, a su vez, puede entregar la cosa convenida y dejar que el otro realice su prestación después de transcurrido un tiempo determinado, durante el cual confía en él" (Hobbes, 2014, p. 109). Esto es lo que el filósofo va a establecer como pactum societatis. Dicho contrato o pactum societatis se ha de materializar en un Estado con poderes absolutos que garantice la libertad imprescindible para cada individuo.

Esto es algo más que consentimiento o concordia; es una unidad real de todo ello en una y la misma persona, instituida por pacto de cada hombre con los demás, en forma tal como si cada uno dijera a todos: autorizo y transfiero a

2. Diego Fernández Peychaux en una nota al pie de página determina: "La voluntad, para Hobbes, es, en cambio, el último apetito"de quien delibera-i.e. la voluntad consiste en "querer hacer"-. Las acciones son "voluntarias" si se siguen del "querer". Pero ello no implica que la voluntad quede eximida de la determinación por causas necesarias" (Peychaux, 2015, p. 64). 
este hombre o asamblea el derecho de gobernarme a mí mismo, con la condición de que vosotros transferáis a él vuestro derecho, y autorizaréis todos sus actos de la misma manera (Hobbes, 2014, p. 141).

Esta renuncia y transferencia de derechos, así como el acto de subordinación, crean una nueva situación legal. Dicho de otra manera, crean el cuerpo político o Estado con derecho a promulgar leyes y hacerlas cumplir, generando así una obligación forzosa en cada uno de los súbditos. De lo anterior, la multitud unida en una persona se denomina commonwealth, aquel gran hombre artificial o, como el mismo Hobbes lo llama, dios mortal, ese Leviatán al cual debemos nuestra paz y nuestra defensa. Por ello, la esencia del Estado - el soberano- el filósofo lo describe así: "Una persona de cuyos actos una gran multitud, por pactos mutuos, realizados entre sí, ha sido instituida por cada uno como autor, al objeto de que pueda utilizar la fortaleza y medios de todos, como lo juzgue oportuno, para asegurar la paz y defensa común" (Hobbes, 2014, p. 141).

Con esto, el pensador inglés explicita que el soberano solo puede ser el soberano, pero que a su vez no está sujeto a sus propias leyes que puede revocar en cualquier momento. Las leyes reciben su autoridad de la voluntad del Estado, de la voluntad del soberano. Él es la ley. De modo que no se producen contradicciones, pues él es el que interpreta las leyes de la naturaleza y las integra a la ley civil sin fallas. Es la única manera como es posible administrar un poder fuerte de forma absoluta y cumplir los requisitos del contrato que suscriben los hombres para salir del estado de guerra.

Hobbes establece dos condiciones y momentos diferentes en la constitución del pacto. El primero es un acto concertado, un compromiso común, un contrato social a través del cual todos renuncian a sus derechos de naturaleza al mismo tiempo. El segundo es la transferencia de esos derechos a una persona o institución, acto que debe ser necesariamente concertado y consensual, constituyéndose en un pacto de unión frente a un objetivo definido, a saber: el de que un poder común garantice a todos el cumplimiento del contrato y el pacto, evitando así recaer en el estado de anarquía y zozobra anterior (Mejía, 2005, pp. 36-37).

Al respecto conviene decir que para nuestro filósofo el Estado surge como un instrumento al sujeto, pues al adjudicarse derechos se puede garantizar la armonía entre los hombres, dado que sin ese contrato social o pacto de individuos libres, resultarían matándose unas a otras, visto que:

(...) la condición del hombre (...) es una condición de guerra de todos contra todos, en la cual cada uno está gobernado por su propia razón, no existiendo nada, de lo que pueda hacer uso, que no le sirva de instrumento para proteger su vida contra sus enemigos. De aquí se sigue que, en semejante condición, cada hombre tiene derecho a hacer cualquier cosa, incluso en el cuerpo de los demás (Hobbes, 2014, pp. 106-107).

Es decir, de las exigencias de la razón surge el Estado a causa de que aquella calcula las posibilidades y ventajas del salir de la condición natural y renunciar a su vez a la libertad y poder del que dispone cada sujeto. No olvidemos que en ese estado natural todos los hombres son iguales y por ende nacen los enfrentamientos o guerras de todos contra todos, porque al permanecer el sujeto en un esfuerzo por lograr la paz aprovecha en un punto las ventajas de la guerra, lo que desarrolla la ley fundamental de la naturaleza.

Por ello, El Estado —ese Leviatán todopoderosogarantizará que eso no ocurra al dejar que cada individuo disfrute de su anhelada libertad, puesto que "este desbordamiento de lo meramente fenomenológico individual está remitido al sujeto, que es quien percibe el estado de guerra como una amenaza constante, al margen del estallido o no de alguna batalla en concreto" (Román, 2013, p. 115). Pero con el hombre artificial, la libertad del súbdito arraiga exclusivamente en las acciones que ha regularizado el soberano; -es decir que- al traspasar los súbditos su derecho al soberano, estos son a la vez autor de cada uno de los actos de quién ha tomado el poder; de aquí viene según Hobbes la facultad del gobernante de promulgar las leyes que mejor le correspondan, ya que al hacerlo -ya sea bajo espada ${ }^{3}$ - está ejecutando lo propio de la ley natural. ${ }^{4}$ Aunque, en ocasiones la racionalidad de los actos del soberano o de los individuos no es la única garantía de la que dispone el pensador en cuestión para la seguridad de ambos, luego "si el soberano ordena a un hombre (...) que se mate, hiera o mutile a sí mismo o que no resista a quienes lo ataquen, o que se abstenga del uso de alimentos, (...) o de cualquier otra cosa, sin la cual no puede vivir, ese hombre tiene libertad para desobedecer" (Hobbes, 2014, 177). Por ello, si se da un caso donde las acciones degeneren y dejen de seguir las normas adecuadas para la preservación, pueden ser expulsados de la sociedad

3. "Quienes dan a un hombre el derecho de gobernar, en plena soberanía, se comprende que le transfieren el derecho de recaudar impuestos para mantener un ejército, y de pagar magistrados para la administración de justicia” (Cf. Hobbes, 2014, p. 113).

4. Cf. Noob, Polsci. 2011. Similitudes y diferencias entre las teorias políticas de Locke y Hobbes. [Entrada en blog]. https://reflexionessociales.wordpress. com/2011/03/04/lockehobbessimildiferen/

$54<$ Universidad de San Buenaventura, Cali, Colombia 
en el caso de los sujetos pactantes, o desobedeciendo cuando se trate del soberano.

Dentro de este contexto encontramos en la lectura del Leviatán un momento en donde se establece la disposición de los hombres a la rebelión, por consiguiente "suele ocurrir, entonces, que cuando el ejercicio del poder otorgado tiene que recuperarse para la salvación pública, sugiere la impresión de un acto injusto, lo cual (cuando la ocasión se presenta) dispone a muchos hombres a la rebeldía" (Hobbes, 2014, pp. 263-264). Lo anterior, es un derivado de una institución imperfecta; en otras palabras, por falta de un poder absoluto. De cierta manera se puede considerar, entonces, que los súbditos tienen derecho a la sublevación contra el Estado si este abusa de su poder y acaba con toda posibilidad de libertad. No olvidemos que la naturaleza humana es la misma dentro y fuera del Estado, por ende:

(...) la obligación de los súbditos con respecto al soberano se comprende que no ha de durar ni más ni menos que lo que dure el poder mediante el cual tiene capacidad para protegerlos. En efecto, el derecho que los hombres tienen, por naturaleza, a protegerse a sí mismos, cuando ninguno puede protegerlos, no puede ser renunciado por ningún pacto (Hobbes, 2014, p. 180).

En esto debemos tener en cuenta que la renuncia que el súbdito hace de su derecho no se convierte o establece en una transferencia del derecho entendido como libertad natural. Igualmente, el soberano no obtiene un poder del que no disfrutaba antes del pacto. En efecto, el pacto no conlleva renunciar a la autodefensa contra la fuerza. Aquí la autoridad del soberano no exceptúa si el ejercicio de dicha autoridad es justo, es así que la libertad en la sociedad civil tiene como límite la justicia pues solo hay obligación de hacer lo que es justo, es decir, lo pactado.

Por tanto, el ejercicio de la resistencia política se encuentra en lo que anteriormente llamamos deliberación, en la facultad de establecer el poder y medir los daños y, no en una libertad formal reconocida a todos los sujetos. Por ello, Hobbes expone que lo que deben perseguir los hombres es una concreta posibilidad de autopreservación y no esas aspiraciones fantasiosas de libertad "garantizadas" por una establecida forma de gobierno, puesto que "la justicia, es decir, la observancia del pacto, es una regla de razón en virtud de la cual se nos prohíbe hacer cualquiera cosa susceptible de destruir nuestra vida: es por lo tanto, una ley de naturaleza" (Hobbes, 2014, p. 121). En definitiva, cuando la preservación no corre riesgos es irracional buscar la resistencia, porque para el autor: "Es contrario a la razón alcanzar la soberanía por la rebelión: porque a pesar de que se alcanzara, es manifiesto que, conforme a la razón, no puede esperarse que sea así, sino antes al contrario; $y$ porque al ganarla en esa forma, se enseña a otros a hacer lo propio" (Hobbes, 2014, p.121). Después de todo, esa irracionalidad no brota de estimar la mayor o menor libertad que un soberano confiere a los súbditos; por el contrario, se da por una conjetura racional de medios y fines que, como explica Hobbes, hace a los hombres conservadores.

De allí que se pueda dar una incompatibilidad entre mantener que el soberano no pacta y que se le puede desobedecer o resistir, ya que ni el poder absoluto ni el quebrantamiento del pacto son la justificación de dichos actos. Los anteriores se basan en un cálculo individual basado en la necesidad natural en la que se balancea la viabilidad de la obediencia y la resistencia; es decir, entre las perversidades del soberano y el peligro de volver a regirse por las normas de guerra. Dicho de otro modo,

(...) frente al poder político y al modelo del Estado, podemos deducir que el derecho a la resistencia como práctica política sería totalmente ilógico e innecesario. Si se llegara a admitir este derecho dentro del Estado, sería tanto como admitir un derecho a la guerra civil reconocido por el Estado, es decir, un derecho a destruir el mismo Estado (Restrepo, 2010, p. 137).

Finalmente, la resistencia no solo es una realidad de hechos sino un instrumento necesario en el sistema político descrito en el Leviatan. Por ello, esta obra hobbesiana es una exaltación a la satisfacción en la que el filósofo busca dejar claro a sus conciudadanos que la libertad, como eje central de la resistencia, funciona como una complicación, puesto que si las necesidades individuales se encuentren satisfechas no hay una oportunidad evidente ni legítima racionalidad para dicho acto de resistencia política y esta, al igual que el pacto, incluso cuando se fusiona en los derechos individuales, es posible que acontezca cuando se produzca la confirmación de una voluntad colectiva.

\section{Pensamiento político de John Locke en el Segundo tratado sobre el gobierno civil}

Gracias a sus principales aportes, el filósofo inglés John Locke llegó a ser considerado como el fundador del empirismo moderno y primer teórico libertario. Esto último se le atribuye por afirmar que los gobiernos surgen de un pacto o contrato que puede ser anulado por los mismos sujetos con el firme propósito de proteger la vida y la propiedad. Es decir, los suscriptores de dicho pacto tienen el derecho de retirar su confianza a quien los gobierna y rebelarse cuando no cumple su función. De ahí que 
además de ser el precursor de la división de poderes de un Estado democrático, abordará magistralmente el derecho de resistencia. Por ello, en este apartado nos enfocaremos en su obra Segundo tratado sobre el gobierno civil. Un ensayo acerca del verdadero origen, alcance y fin del gobierno civil, considerada por muchos como una respuesta a la postura absolutista de Hobbes. En el texto antes citado, el pensador intenta fundamentar no solo filosóficamente sino también políticamente la legitimidad del Estado a partir de su origen, llegando así a exponer los razonamientos básicos de su liberalismo.

Locke inicia su labor buscando una respuesta a qué es el poder, particularmente el poder político, no sin antes analizar a los sujetos en el estado de naturaleza, puesto que la ley natural es una e invariable para todos los hombres incluidos los legisladores y soberanos, dado que, en palabras del filósofo:

(...) el estado de naturaleza tiene una ley de naturaleza que lo gobierna y que obliga a todos; y la razón que es esa ley, enseńa a toda la humanidad que quiera consultarla, que siendo todos los hombres iguales e independientes, ninguno debe dañar a otro en lo que atañe a su vida, salud, libertad o posesiones (Locke, 1994, p. 38).

Cabe señalar que la ley de naturaleza rige por la paz y la preservación de los hombres. Es así que en este estado la ley se les ha dado a cada uno de manera tal que es legítimo castigar a quien cometiere una ofensa o a los transgresores de la mencionada ley. Tal derecho es el de autoconservación, pues con este se da la libertad de hacer todo lo que se estime razonable previniendo a su vez que el crimen o la ofensa vuelva a ser cometida, aunque también tiene como fin que los hombres se abstengan de violar los derechos de los demás y se dañen mutuamente.

De igual modo, vemos que a diferencia de Hobbes para quien la condición del hombre es una condición de guerra de todos contra todos-, el estado de naturaleza de Locke se encuentra regulado por la razón, por lo cual los seres creados por Dios están en un estado de "perfecta libertad y de igualdad en el que todo poder y jurisdicción son recíprocos" (Cf. Locke, 1994, p. 36). Reconoce de igual forma que los hombres al nacer no se encuentran sujetos a un poder: "Yo voy todavía mas allá y afirmo que los hombres se hallan naturalmente en un estado así, y que en él permanecen ${ }^{5}$ hasta que por su propio consentimiento, se hacen así mismos miembros de una sociedad política" (Locke, 1994, p. 45). Es así que este estado natural del filósofo libertario es placentero y pacífico, por lo tanto es un estado prepolítico.

Lo anterior implica que los sujetos podrían vivir ordenada y moralmente sin establecer una sociedad política directa. Igualmente, podrían disfrutar de su propiedad, siempre y cuando los demás también puedan satisfacer sus necesidades.

En efecto, el hombre natural de Locke no es un violento hobbesiano sino un hombre gentil que posee virtudes de respeto a las pertenencias ajenas y puede vivir en paz conforme a la razón, sin un poder terrenal común y superior a todos. Sin embargo, este apacible comportamiento podrá convertirse en un estado de guerra porque aunque si bien es un ser razonable, justo y con derecho a destruir a quien llegue con amenaza, existen hombres que no se guían por la ley común de la razóny por ende su única regla es la de la fuerza y la violencia. Así, “(...) la fuerza que se ejerce sin derecho y que atenta contra la persona de un individuo produce un estado de guerra, tanto en los lugares donde hay un juez común, como en los que no lo hay" (Locke, 1994, p. 49). Varnagy resume lo anterior de la siguiente manera:

En el estado de naturaleza un hombre tiene derecho a juzgar y castigar a quien no respeta la ley natural, convirtiéndose el transgresor en un peligro para la humanidad (...). En otras palabras, cualquier hombre en el estado de naturaleza tiene el poder de matar a un asesino o castigar a un delincuente pues este renunció a la razón y a la ley (Varnagy, 2000, p. 55).

Es decir, existe un estado de paz siempre y cuando no haya un uso inadecuado de la fuerza. Ese uso inadecuado es el uso de la fuerza en el que la preservación o la autoconservación no se ven amenazadas. En definitiva, el estado de naturaleza se transforma en un estado de guerra cuando los sujetos atentan contra la propiedad de otros,

(...) es por lo que, con gran razón, los hombres se ponen a sí mismos en un estado de sociedad y abandonan el estado de naturaleza. Porque allí donde hay una autoridad, un poder terrenal del que puede obtenerse reparación apelando a él, el estado de guerra queda eliminado y la controversia es decidida por dicho poder (Locke, 1994, p. 50).

Por ello, para salir de ese estado los individuos convienen un pacto o contrato que en consecuencia construye una sociedad civil y a su vez la comunidad política.

Esto es lo que saca a los hombres del estado de naturaleza y los pone en un Estado: el establecimiento de un juez terrenal con autoridad para decidir todas las controversias y para

5. Entiéndase aquí el estado de naturaleza

$56<$ Universidad de San Buenaventura, Cali, Colombia 
castigar las injurias que puedan afectar a cualquier miembro del Estado y dicho juez es la legislatura, o el magistrado nombrado por ella (Locke, 1994, pp. 104-105).

Esto es, la sociedad en estado natural ostenta la capacidad de organizarse de manera armoniosa sin recurrir a un orden político. En tal caso, lo que obliga a instaurarlo es la imposibilidad de la misma sociedad de mantener su orden natural cuando este es amenazado por enemigos. Por ello, el contrato se efectúa para garantizar la seguridad de la propiedad ya sea la vida, los bienes o la misma libertad. Acá la legitimación y la autoridad del Estado surgen por la superación de inseguridad planteada por Hobbes y la protección de bienes que desarrolla Locke. Pero hay más. El poder político admitido deriva del contrato entre los miembros de la sociedad, pero en él los hombres no se someten a un gobierno sino que se da una relación de confianza en la que de una u otra forma se accede a estar atado por la voluntad de la mayoría. ${ }^{6}$ Es así que,

Locke llama al acuerdo originario agreement, contract o compact, que son sinónimos de pacto y se refiere a él como un solo acto. (...).En efecto, el contrato lockeano, junto con constituir la sociedad política o pueblo, establece el régimen político. Pero mientras la acción constitutiva de la sociedad civil es irrevocable, la decisión mayoritaria que crea el gobierno o régimen político es revocable, porque es una delegación. Así, en un solo acto de consentimiento, los individuos crean el pueblo o cuerpo político y, a la vez, a través de la regla mayoritaria, se le atribuye el poder legislativo a un hombre o a una asamblea de hombres (Godoy, 2004a, p. 164).

De manera que el ascenso del estado de naturaleza indica que los sujetos han renunciado a su poder de cumplir por sí mismo la ley natural para su protección y los transfirieron a la sociedad civil. "Este acto de segregación es voluntario y, por lo tanto, enteramente libre (Godoy, 2004a, p. 165)". Pero el gobierno queda limitado y cumple de esta manera una sola función, a saber, proteger pero sin intervenir en la vida de los sujetos siempre y cuando no haya disputas, permitiendo así que cada uno persiga sus intereses aunque el poder del gobierno se funda en los poderes que le transfirieron. Hay que establecer que:

El poder absoluto y arbitrario o gobernar sin leyes establecidas, no puede ser compatible con los fines de la sociedad y del Gobierno. Los hombres no abandonarían la libertad del estado de naturaleza, ni se someterían a una norma, si no fuera porque buscan con ello preservar sus vidas, sus libertades y sus fortunas, y porque quieren que su paz y tranquilidad sean aseguradas por reglas establecidas en lo concerniente a su derecho y a su propiedad (Locke, 1994, p.144).

A partir de que los hombres se incorporan a una sociedad con la finalidad de proteger su propiedad — su vida, libertad y bienes - , preguntar sobre cómo protegerse del daño y el agravio provenientes de quien tiene un poder mayor para causar tales males es para Locke manifestar la disidencia y la rebelión (Cf. Locke, 1994, p. 108). Por ello, el filósofo justifica la sublevación cuando el Gobierno se vuelve tiránico y llega a romper con el contrato. "En términos lockeanos, eso significa que no gobierna en conformidad con la ley que se origina en el poder legislativo, y que, por lo mismo, no reconoce ni la supremacía de ese poder ni el imperio del derecho" (Godoy, 2004b, p. 272). Es así que el derecho de "la rebelión, es una oposición, no a las personas, sino a la autoridad basada en las constituciones y leyes del gobierno" (Locke, 1994, pp. 216-217) convirtiéndose así en un acto moral porque "(...) ningún hombre, ninguna sociedad de hombres tiene el poder para renunciar a su propia preservación, ni para entregar los medios de conseguirla poniéndolos bajo el dominio arbitrario y absoluto de otro" (Locke, 1994, p. 155).

El derecho a resistir es un derecho natural que no se puede ejercer contra un gobierno legítimo. En virtud de ello, el pueblo que subsiste por comunidad así se dé la ruptura del gobierno, es quien decide cuando se ha roto la confianza. Ergo, el deber de la rebelión se encuentra "Porque los que tienen el poder, cuando maquinan contra el pueblo ejerciendo una autoridad que el pueblo jamás puso en sus manos (...) están haciendo algo a lo que no tienen derecho" (Locke, 1994, 170). De alguna manera, la resistencia es el poder supremo que tiene una comunidad para salvarse a sí misma frente a posibles amenazas y malas intenciones que provengan de cualquier persona, incluso de los mismos legisladores, porque quizás estos sean tan insensatos o malvados que sean capaces de llevar a cabo proyectos que contraríen la libertad y la propiedad de los súbditos. Según lo antes mencionado,

La rebelión es un derecho general de la humanidad, pero para actuar coherentemente, los rebeldes deben guiarse por la decisión popular mayoritaria. Esta decisión les permite actuar como una comunidad independiente y no como la suma de individuos aislados. La rebelión es el momento en que el derecho del pueblo como cuerpo político unificado se solapa con las obligaciones que toda persona tiene como ser humano de asistir a los demás; asimismo, el derecho a proteger lo propio se corresponde con el deber común de actuar contra la injusticia (Pereyra, 2018, 194).

6. Para Locke, la mayoría es interpretada como el gobierno de los propietarios de tierras, comerciantes y personas adineradas, pues los desposeídos pertenecían a una especie de hombres irracionales y por tanto inferiores que al no tener propiedad no tenían libertad. 
Más delante Locke también admitirá que cuando un pueblo sufre y se expone a abusos por causa de un poder arbitrario, la rebelión se dará, pues al ejecutar esta acción se le estará devolviendo al pueblo el poder que cedió en un determinado momento. Se regresa el derecho de retomar su libertad original y establecer un nuevo cuerpo de gobierno más apropiado que le suministre el fin que perseguían al unirse, a saber: la protección y seguridad. Además, que el mismo pueblo juzgue — como ya se mencionó- implica que el derecho de resistir contra los tiranos prevalece, pero se debe tener presente que no existe tal derecho si hay posibilidad de recurrir a la ley

(...) pues el uso de la fuerza solo está justificado cuando a un hombre no se le permite buscar remedio mediante recurso legal; y que sin más hace uso de su fuerza, se pone a sí mismo en estado de guerra y hace que sea legal toda resistencia que se le oponga (Locke, 1994, p. 202).

Como lo explica Godoy: "Para Locke el poder político decente y legítimo es aquel que está sometido al escrutinio de los gobernados, que en última instancia disponen del derecho de resistencia" (Godoy, 2004b, p. 278). La sociedad política está por el acuerdo de la misma comunidad de nombrar autoridades, y si esta llega a ser relevada de su función mediante la fuerza, se está violentando el acuerdo social, es ahí donde los sujetos tienen el derecho de rebelarse. Por tanto, para el pensador inglés, la fuerza sin derecho es necesaria enfrentarla con otra fuerza y de esta manera recuperar el camino de la ley.

\section{Conclusiones}

Señalemos, en pocas palabras, las similitudes y a su vez diferencias que podemos encontrar entre el pensamiento de Thomas Hobbes y John Locke. Iniciamos con el estado de naturaleza y en él la ley natural, porque en Hobbes la naturaleza ha hecho a los hombres iguales y de dicha igualdad se deriva la ecuanimidad en la consecución de los fines, principalmente su autoconservación, ${ }^{7}$ aunque de esa igualdad puede emanar la desconfianza debido a que si dos hombres desean la misma cosa y no la pueden disfrutar al tiempo se convertirán en enemigos que buscarán aniquilarse, generando de esta manera una condición o estado de guerra en el que nada es injusto, puesto que “(...) donde no hay poder común, la ley no existe: donde no hay ley, no hay justicia" (Hobbes, 2014, p. 104). No obstante, hay una posibilidad de salir de ese estado, en parte por las pasiones como el temor a la muerte y el deseo de las cosas para una vida confortable y en parte por la razón quien sugiere las normas de paz — leyes de la naturaleza — que se pueden llegar por mutuo consenso.

Por su parte, el estado de naturaleza en Locke es un estado de igualdad en el que todos tienen el mismo poder y nadie disfruta más que otros. Así, “(...) es este un estado de perfecta libertad para que cada uno ordene sus acciones y disponga de posesiones y personas como juzgue oportuno, dentro de los límites de la ley de naturaleza, sin pedir permiso ni depender de la voluntad de ningún otro hombre" (Locke, 1994, p. 36).

Esa igualdad proviene de la condición natural del hombre. Por ello, no cabe la subordinación ni el sometimiento de unos sobre otros. A pesar de lo anterior, el hombre no tiene la libertad de destruirse a sí mismo ni a ninguna criatura de su posesión, a excepción de que sea requerido por la preservación. Porque "(...) el estado de naturaleza tiene una ley de naturaleza que lo gobierna y que obliga a todos" (Locke, 1994, p. 38). La mencionada ley es la razón, pues al estar todos dotados de las mismas facultades, cada uno se ve obligado a no destruirse por su propia voluntad. Entonces mientras que Hobbes teoriza que la ley natural se asigna consecutivamente solo por medio de un procedimiento en el cual la razón es el factor principal, Locke asume que el estado natural reconoce la ley natural y el sujeto es su propio ejecutor en estado natural.

De lo anterior surge la ejecución de un pacto o contrato para salir del estado de naturaleza, de ese estado de guerra. Así que Hobbes propone un pacto — natural — procedente del egoísmo natural del hombre en potestad de la razón para la creación de un "monstruo" cuyo poder es ilimitado y sus actos implacables al momento de restringir a los hombres por su facultad de generar miedo. Para Locke el pacto es social, pues este se establece entre los hombres para instaurar un gobierno que sea capaz de aplicar de forma objetiva una ley común entre los miembros de un Estado. Ese gobierno se forma con el consentimiento de los miembros de la comunidad y con separación de poderes para evitar la concentración del poder. Si se llega a incumplir el contrato, la comunidad está obligada a removerlo y establecer otro gobierno. Lo anterior no es posible desde el enfoque hobbesiano, pues su artificio natural tiene que concentrar el poder absoluto para así desempeñar ciertamente su función natural.

En cuanto al concepto de resistencia, con Locke encontramos una justificación al derecho del pueblo a resistirse de forma legítima en contra de "la autoridad basada en las

7. Cabe señalar que dentro de la concepción individualista del hombre que plantean tanto Hobbes como Locke la finalidad es la autoconservación. 
constituciones y leyes del gobierno; (...) que por la fuerza quieren justificar la violación de dichas leyes" (Locke, 1994, p. 217). Esto constituye un estado de guerra del gobernante con el pueblo y frente a esto es cuando el pueblo obtiene el derecho legítimo transformándolo al mismo tiempo en deber de resistir por la fuerza si es necesario. Este derecho de resistencia no es político ni derivado del pacto social, sino un derecho natural contra el gobernante cuando se ha puesto en guerra con el pueblo.

Para Hobbes, en la naturaleza del pacto es claro que no hay posibilidad de rebelarse contra el poder del soberano, pues el principio del poder se fundamenta en los pactos de todos entre sí. Los súbditos están obligados a una obediencia a las leyes pues el poder del soberano es absoluto y resistirse a él es negar su autoridad, lo que sería un acto injusto. "Nadie tiene libertad para resistir a la fuerza del Estado, en defensa de otro hombre culpable o inocente" (Hobbes, 2014, p. 179). Luego, en el hecho de un grupo de súbditos que de forma "injusta" se resista al soberano, la extensión de dicha resistencia y esta agrupación no va a representar una nueva injusticia; empero, el único medio por el que el soberano se despoje legítimamente de su autoridad es que todos los hombres, sin excepción, consigan un acuerdo contra su potestad, y para ello, es indispensable que el soberano esté de acuerdo en renunciar a sus deberes; así que aunque los súbditos por medio de un restablecimiento de la guerra pueden derrocar al soberano, para Hobbes esta acción se está haciendo sin un derecho legítimo.

En definitiva, en Locke la finalidad de un gobierno es el bien, por ello si tiránicamente no cumple su propósito y pasa por encima de sus ciudadanos ellos se ven obligados a derrocarlo y crear uno nuevo, además se considera culpable - gobernante o súbdito- a quien intente invadir por la fuerza los derechos ya sean del soberano o del pueblo generando un pretexto para que elimine la constitución y régimen de gobierno; por el contrario, el Estado para Hobbes “...puede perecer por enfermedades internas" (Hobbes, 2014, p. 263) que pueden hacerlo desaparecer, dado que estas enfermedades ocasionan el desorden e impiden que el soberano cumpla con su función, a saber, ejecutar la ley natural e instaurarse como poder coercitivo.

\section{Referencias}

Godoy, O. (2004a). Libertad y consentimiento en el pensamiento político de John Locke. Revista de ciencia política (Santiago) 24.2: 159-182. https://scielo.conicyt.cl/scielo.php?script $=$ sci_arttext $\&$ pid $=$ S07 18 090X2004000200009\#ref138
Godoy, O. (2004b). Absolutismo, tiranía y resistencia civil en el pensamiento politico de John Locke. Estudios Públicos, (96), 147-148.

Hobbes, T. (2014). Leviatán. O de la materia, forma y poder de una republica eclesiástica y civil. Trad. Manuel Sánchez Sarto. Buenos Aires: Fondo de Cultura Económica. Ed. $9^{\circ}$.

Locke, J. (1994). Segundo tratado sobre el tobierno civil. Un ensayo acerca del verdadero origen, alcance y fin del gobierno civil. Madrid: Ediciones Altaya, S.A

Lukac de Stier, M. (2015). Hobbes y la construcción racional del Estado. Primeras Jornadas de Intercambio Académico. Universidad Católica Argentina. Facultad de Filosofía y Letras, Buenos Aires. Disponible en: http://bibliotecadigital. uca.edu.ar/repositorio/ponencias/hobbes-construccionracional-estado.pdf

Mejía, O. (2005). La filosofía politica de John Rawls [i]: La teoría de la justicia. Con Rawls y contra Rawls: una aproximación a la filosofía política contemporánea, 29.

Pereyra, G. (2018). Locke y la teoría de la rebelión popular. Estudios políticos (México) 44: 185-201. http://www.scielo.org. mx/scielo.php?pid=S018516162018000200185\&script=sci_arttext\&tlng=pt

Peychaux, D. F. (2015). Castigar y hostilizar. Corolarios del derecho al castigo en Leviatán de Thomas Hobbes. Anacronismo e irrupción, 2015, vol. 5, no 9, p. 54-78. https:// publicaciones.sociales.uba.ar/index.php/anacronismo/ article/view/1516/1382

Peychaux, D. F. (2013). Thomas Hobbes: libertad, miedo y resistencia politica. Ingenium: Revista electrónica de pensamiento moderno y metodología en historia de las ideas (7): 149-170. https://dialnet.unirioja.es/servlet/revista?codigo $=14563$

Restrepo, P. C. (2010). Poder político, contrato y sociedad civil: de Hobbes a Locke. Revista de la Facultad de Derecho y Ciencias Políticas 38.108: 123-154. https://revistas.upb.edu.co/ index.php/derecho/article/view/605/543

Román, J. M. S. (2013). Acerca del concepto de naturaleza en Thomas Hobbes: derecho natural y ley natural en El Leviatán. Espíritu: cuadernos del Instituto Filosófico de Balmesiana, 62(145), 95-123.

Santos, J. (2013). Acerca del concepto de naturaleza en Thomas Hobbes: derecho naturaly ley natural en El Leviatán. Espíritu: cuadernos del Instituto Filosófico de Balmesiana, 62 (145), 95-123.

Varnagy, T. (2000). Capitulo II. El pensamiento politico de John Locke y el surgimiento del liberalismo. CLACSO, Consejo Latinoamericano de Ciencias Sociales. http://biblioteca. clacso.edu.ar/gsdl/collect/clacso/index/assoc/D954. dir/3cap2.pdf 